\title{
Short and lifetime cardiovascular risk estimates: Same wine, different bottles. Do we have the COURAGE to abandon risk scores?
}

\author{
Khurram Nasir, MD, MPH, ${ }^{\mathrm{a}, \mathrm{b}, \mathrm{c}, \mathrm{d}}$ and Michael J. Blaha, $\mathrm{MD}, \mathrm{MPH},{ }^{\mathrm{d}}$ \\ a Center for Prevention and Wellness Research, Baptist Health Medical Group, Miami Beach, FL \\ ${ }^{b}$ Department of Medicine, Herbert Wertheim College of Medicine, Florida International \\ University, Miami, FL \\ c Department of Epidemiology, Robert Stempel College of Public Health, Florida International \\ University, Miami, FL \\ d The Johns Hopkins Ciccarone Center for the Prevention of Heart Disease, Baltimore, MD
}

Received Dec 4, 2013; accepted Dec 4, 2013

doi: $10.1007 / \mathrm{s} 12350-013-9838-4$

Cardiovascular disease (CVD) is the leading cause of mortality worldwide with coronary heart disease disease (CHD) accounting for nearly half of all CVD deaths. ${ }^{1}$ Because half of first major coronary events occur in asymptomatic individuals, clinicians who want to implement appropriate primary prevention therapy must be able to accurately identify " at risk' individuals. Currently major CVD risk stratification based strategies such as the Framingham risk score (FRS) as well and the recent 2013 ACC/AHA CVD risk score form the cornerstone of CVD risk assessment and guide the intensity of preventive strategies based on estimates of 10-year risk. ${ }^{1,2}$ However, extensive literature has clearly documented the uncertainty of these short-term predictive models and the predilection to miss a large portion of those truly at risk, especially younger individuals and women. $^{3-6}$

To overcome the limitations of the short-term risk, a new concept that is gaining popularity is to focus on lifetime risk estimates that potentially can allow identification of younger individuals with low short-term but high lifetime risks, who may be may benefit from intensive lifestyle modification as well likely to more accurately reassure those at low lifetime risk of their CHD risk. ${ }^{7,8}$

In this issue of the Journal, Hulten et al. ${ }^{9}$ proposed to assess the utility of this novel approach by reporting

\footnotetext{
Reprint requests: Khurram Nasir MD, MPH, Center for Prevention and Wellness Research, Baptist Health Medical Group, 1691 Michigan Ave Suite 500; Miami Beach, FL 33139; knasir1@jhmi.edu; J Nucl Cardiol 2014;21:46-9. 1071-3581/\$34.00

Copyright (C) 2013 American Society of Nuclear Cardiology.
}

differences in detection of early coronary atherosclerotic across low vs. high lifetime risk. The study can be summarized by the main findings: (1) among those with low short-term risk (10-year risk $\leq 10 \%)$, individuals can be reclassified about equally (50\% each) between high lifetime risk and low lifetime risk, (2) those with low short-term/high lifetime risk group had a "higher" $(P<0.001)$ prevalence of the presence of early atherosclerotic disease $(41 \%)$ compared to the low shortterm/low lifetime risk group (32\%). Based on these findings the authors infer the calculation of lifetime risk may better identify patients at risk due to higher prevalence of CAD among patients at high lifetime risk and support the argument for more aggressive preventive strategies in this specific group.

The following aspects of the study deserve further comment.

What is the added impact of lifetime risk assessment among those at low short-term (10 year) risk? If the presence of atherosclerosis is considered a surrogate for risk, using the study findings ${ }^{11}$ demonstrated in Figure 1, 37/100 individuals at low life time risk will have early atherosclerotic disease at will be have increased otherwise unidentified risk. Of these 20 (54\%) were considered high LTR. However, nearly equal number $(n=17,46 \%)$ was observed among the group considered at low LTR. Is this difference clinically meaningful? Furthermore, the overall accuracy (true positives and true negatives) for the presence/ absence of any coronary atherosclerosis with additional stratification with lifetime risk assessment is estimated to be $55 \%$, which one may equate to a coin toss (Table 1). 
Table 1. Diagnostic performance of life time risk assessment (LTR) in identifying those with and without subclinical coronary atherosclerotic disease

\section{Presence of subclinical} atherosclerotic disease
Presence of subclinical atherosclerotic disease

$\begin{array}{llll}\text { High LTR } & 20(54 \%) & 28(44 \%) & 48(48 \%) \\ \text { Low LTR } & 17(46 \%) & 35(56 \%) & 52(52 \%) \\ & 37(100 \%) & 63(100 \%) & 100(100 \%)\end{array}$

aBased on data from Hulten et al. ${ }^{9}$

Sensitivity $=54 \%$

Specificity $=56 \%$

Positive predictive value $=41 \%$

Negative predictive value $=67 \%$

Accuracy $=55 \%$

This leads us to ponder the following questionif the goal is to accurately identify atherosclerotic risk for deciding further management strategies regarding whom to treat and not treat, should we even bother with LTR assessment? Why doesn't the LTR approach perform better? We believe that these models offer no advance because they fail to integrate previous time-dependent risk exposure. Rather, like the FRS and the new 2013 AHA-ACC CVD risk calculator, they continue to emphasize one-time measurement of traditional risk factors and typically among middle-age individuals. They thus suffer from the same inherit limitations of other risk estimates based solely on officebased assessment risk factors and addition of biomarkers such as high sensitivity C-reactive protein. ${ }^{10}$

Can we reassure individuals with low lifetime risk that they are free of atherosclerotic disease? In our humble view, we cannot. Hulten et al brings to our attention the fact that in the absence of risk factors, and thus "low life time risk" status, the risk of presence of early atherosclerotic disease is not insignificant and can falsely reassure nearly one-third individuals. Of note, approximately $15 \%$ of these young individuals with low lifetime risk had at least moderate degree of coronary atherosclerosis (as denoted by CAC $>100$ ), which has been widely accepted to be associated with a very high short-term risk of cardiac events and mortality.

What is the prognostic value of coronary atherosclerosis detected in one third of those at low lifetime risk? This is a key question. The critics can rightly argue that the goal of these LTR assessment strategies is to delineate risk, and value of the presence of atherosclerotic disease noted in one-third of those with low LTR may have little impact on future cardiac events. Unfortunately, as acknowledged by the authors, due to the shorter duration of 2 years and low events within this young, asymptomatic population, this key question remained unanswered in the current study.

However there is data available that can guide us on this specific issue. Nasir et al. ${ }^{11}$ studied a cohort of 44,052 asymptomatic self-referred individuals referred for CAC testing and subsequently followed for all-cause mortality over a mean follow up of $5.6 \pm 2$ years. Individuals with 0 risk factors (i.e., low life time risk) and elevated CAC, a feature seen in nearly $15 \%$ of these individuals, had a mortality rate of $16.89 / 1,000$ person-years, as compared to those traditionally considered at higher risk ( $\geq 3$ risk factors) and CAC 0 had a mortality rate of 2.72/1,000 person-years. This study has however limited due to selfreported risk factor status, potential referral bias, and lack of CHD-specific mortality. However, these findings were recently verified in the prospective multi-ethnic study of atherosclerosis (MESA) cohort. ${ }^{12}$ In this study, there was a strikingly similar prevalence of coronary artery atherosclerotic disease (CAC $>0$ ) of $32 \%$ as reported by Hulton et al. in this study among those with zero-risk factors. In a median follow-up slightly less than 10 years (7.5 years), in this group with no risks factors, likely to be considered at low "lifetime" risk, the estimated shortterm (10 year) all CHD risk ranged from 3 to $11 \%$ across the spectrum of increasing CAC burden. ${ }^{14}$ This evidence clearly demonstrates that one cannot reliably equate absence of risk factors to low risk of CHD and supports future guidelines to consider identifying underlying atherosclerotic burden for earlier preventive strategies in this traditionally low risk group.

How can we identify a truly "low risk" individual? A major goal of CVD risk stratification strategies is not only to accurately identify those at risk for early initiation of preventive therapies, but also to appropriately identify individuals at truly low risk, among whom the yield of preventive pharmacotherapies may be limited and for using less healthcare resources in 
a population of patients unlikely to receive net benefit from intervention.

In this regard, CAC testing provides additional value over risk score estimates. The "Power of $\mathrm{CAC}=0$ " confers a very low risk for future CVD events shown by a series of studies including a large meta-analysis, retrospective, and prospective studies with very low event rate of $\sim 1$ per 1000 patient-years $(\sim 1 \% \text { 10-year event rate })^{13-15}$. However the true value of $\mathrm{CAC}=0$ lies appears to be realized in recent studies by accurately "de-risking" individuals already deemed high risk enough to be considered for lifelong preventive medications such as those with multiple risk factors, ${ }^{11,16-18}$ elderly, ${ }^{19}$ dyslipidemia, considered for polypill $^{20}$ as well as diabetics. ${ }^{21,22} \mathrm{~A}$ common theme in all these studies is that a sizeable proportion of those traditionally considered at high risk have no signs of early atherosclerotic disease $(\mathrm{CAC}=0)$, an extremely low risk of incident CVD, and-as a result-an unacceptably high number to treat (NNT) to prevent one cardiac event. ${ }^{23-25}$ For example Silverman estimated that even among individuals with 10-year FRS of $>20 \%$, the absence of CAC was associated with an actual risk of $2.5 \%$ in next 10 years and NNT of $285 .{ }^{12}$ These findings should result in more debate among the policy makers to re-assess if we can afford the luxury to treat a large number of individuals to prevent few events and whether the power of $\mathrm{CAC}=0$ can help in prioritizing how best to allocate our limited resources.

Is it Time for Paradigm Shift for Personalized Risk Assessment Strategies? The finding from Hulten et al support the emerging notions the decision-making process based on traditional risk factors (including assessment of LTR) to accurately determine early atherosclerotic disease, future risk of clinical CVD events, and as a result subsequent intensity of primary prevention as such assessments fall significantly short. With overwhelming evidence suggesting that these varying risk calculations based on traditional risk factors are clearly comparable to the "same wine, different bottles" analogy, we believe it's time to seriously consider a paradigm shift where detection of subclinical atherosclerosis could serve as the initial step in evaluating cardiovascular risk. ${ }^{25,26}$ Our message is very clear: since risk factors and biomarkers cannot really rule out disease, they can only be used to raise risk estimates, and, thus, are inextricably tied to more treatment and unwanted downstream consequences. In this situation, prior to labeling one as low or high LTR, CAC testing provides an excellent opportunity to guide appropriate therapeutic choices by matching one's clinical risk to limit both under and overtreatment.
We need to realize that in the current era we need highly efficient tools to inform beyond making wild guesstimations (FRS, LTR, etc.). The question is, do we have the COURAGE to use them?

\section{References}

1. National Cholesterol Education Program (NCEP). Expert Panel on detection, evaluation, and treatment of high blood cholesterol in adults (Adult Treatment Panel III). Third report of the National Cholesterol Education Program (NCEP) Expert Panel on detection, evaluation, and treatment of high blood cholesterol in adults (Adult Treatment Panel III) final report. Circulation 2002;106:3143-421.

2. Goff DC Jr, Lloyd-Jones DM, Coady S, D'Agostino RB Sr, Gibbons R, Greenland P, Lackland DT, Levy D, O’Donnell CJ, Robinson J, Schwartz JS, Smith SC Jr, Sorlie P, Shero ST, Stone NJ, Wilson PW. ACC/AHA guideline on the assessment of cardiovascular risk: a report of the American College of Cardiology/ American Heart Association Task Force on Practice Guidelines. J Am Coll Cardiol 2013. doi:10.1016/j.jacc.2013.11.005.

3. Nasir K, Michos ED, Blumenthal RS, Raggi P. Detection of highrisk young adults and women by coronary calcium and national cholesterol education panel-III guidelines. J Am Coll Cardiol 2005;46:1931-6.

4. Michos ED, Nasir K, Braunstein JB, Rumberger JA, Budoff MJ, Post WS, Blumenthal RS. Framingham risk equation underestimates subclinical atherosclerosis risk in asymptomatic women. Atherosclerosis 2006;184:201-6.

5. Nasir K, Vasamreddy C, Blumenthal RS, Rumberger JA. Comprehensive coronary risk determination in primary prevention: an imaging and clinical based definition combining computed tomographic coronary artery calcium score and Framingham/ NCEP risk score. Int J Cardiol 2006;110:129-1236.

6. Schlendorf KH, Nasir K, Blumenthal RS. Limitations of the Framingham risk score are now much clearer. Prev Med 2009;48:115-6.

7. Berry JD, Dyer A, Cai X, Garside DB, Ning H, Thomas A, Greenland P, Van Horn L, Tracy RP, Lloyd-Jones DM. Lifetime risks of cardiovascular disease. N Engl J Med 2012;366:3219.

8. Persell SD, Zei C, Cameron KA, Zielinski M, Lloyd-Jones DM. Potential use of 10-year and lifetime coronary risk information for preventive cardiology prescribing decisions: a primary care physician survey. Arch Intern Med 2010;170:470-7.

9. Hulten E, Villines TS, Cheezum MK, Berman DS, Dunning A, Achenback S, Al-Mallah M, Budoff MJ, Callister TQ, Cademartiri F, Chang HJ, Cheng VY, Chinnaiyan K, Chow BJ, Cury RC, Delago A, Feuchtner F, Hadamitzky M, Hausleiter J, Kaufmann PA, Kim YJ, Leipsic J, Lin FY, Maffei E, Plank F, Raff GL, Shaw LJ, Min JK. Calcium score, coronary artery disease extent and severity, and clinical outcomes among low Framingham risk patients with low versus high lifetime risk: results from the CONFIRM registry. J Nuc Cardiol 2013. doi:10.1007/s 12350-013-9819-7.

10. Yousuf O, Mohanty BD, Martin SS, Joshi PH, Blaha MJ, Nasir K, Blumenthal RS, Budoff MJ. High-sensitivity C-reactive protein and cardiovascular disease: a resolute belief or an elusive link? J Am Coll Cardiol 2013;62:397-408.

11. Nasir K, Rubin J, Blaha MJ, Shaw LJ, Blankstein R, Rivera JJ, Khan AN, Berman D, Raggi P, Callister T, Rumberger JA, Min J, 
Jones SR, Blumenthal RS, Budoff MJ. Interplay of coronary artery calcification and traditional risk factors for the prediction of all-cause mortality in asymptomatic individuals. Circ Cardiovasc Imaging 2012;5:467-73.

12. Silverman MG, Blaha MJ, Krumholz HM, Budoff MJ, Blanstein R, Sibley CT, Agatston AS, Bluemthal RS, Nasir K. Impact of coronary artery calcium on coronary heart disease events in individuals at the extremes of traditional risk factor burden: the multiethnic study of atherosclerosis (MESA). Eur Heart J 2013 (in press).

13. Blaha M, Budoff MJ, Shaw LJ, Khosa F, Rumberger JA, Berman D, Callister T, Raggi P, Blumenthal RS, Nasir K. Absence of coronary artery calcification and all-cause mortality. JACC Cardiovasc Imaging 2009;2:692-700.

14. Sarwar A, Shaw LJ, Shapiro MD, Blankstein R, Hoffman U, Cury RC, Abbara S, Brady TJ, Budoff MJ, Blumenthal RS, Nasir K. Diagnostic and prognostic value of absence of coronary artery calcification. JACC Cardiovasc Imaging 2009;2:675-88.

15. Budoff MJ, McClelland RL, Nasir K, Greenland P, Kronmal RA, Kondos GT, Shea S, Lima JA, Blumenthal RS. Cardiovascular events with absent or minimal coronary calcification: the multiethnic study of atherosclerosis (MESA). Am Heart J 2009;158:554-61.

16. Graham G, Blaha MJ, Budoff MJ, Rivera JJ, Agatston A, Raggi P, Shaw LJ, Berman D, Rana JS, Callister T, Rumberger JA, Min J, Blumenthal RS, Nasir K. Impact of coronary artery calcification on all-cause mortality in individuals with and without hypertension. Atherosclerosis 2012;225:432-7.

17. McEvoy JW, Blaha MJ, Rivera JJ, Budoff MJ, Khan AN, Shaw LJ, Berman DS, Raggi P, Min JK, Rumberger JA, Callister TQ, Blumenthal RS, Nasir K. Mortality rates in smokers and nonsmokers in the presence or absence of coronary artery calcification. JACC Cardiovasc Imaging 2012;5:1037-45.

18. Martin SS, Blaha MJ, Blankstein R, Agatston AA, Rivera JJ, Virani VS, Ouyang P, Jones SR, Blumenthal RS, Budoff MJ, Nasir K. Dyslipidemia, coronary artery calcium, and incident atherosclerotic cardiovascular disease: implications for statin therapy from the multi-ethnic study of atherosclerosis. Circulation 2013. doi:10.1161/CIRCULATIONAHA.113.003625.

19. Tota-Maharaj R, Blaha MJ, McEvoy JW, Blumenthal RS, Muse ED, Budoff MJ, Shaw LJ, Berman DS, Rana JS, Rumberger J, Callister T, Rivera J, Agatston A, Nasir K. Coronary artery calcium for the prediction of mortality in young adults $<45$ years old and elderly adults $>75$ years old. Eur Heart J 2012;33:2955-62.

20. Bittencourt M, Blaha MJ, Blankstein R, Budoff MJ, Vargas J, Blumenthal RS, Agatston AA, Nasir K. Polypill therapy, subclinical atherosclerosis, and cardiovascular events-implications for the use of preventive pharmacotherapy: multi-ethnic study of atherosclerosis (MESA). J Am Coll Cardiol 2013. doi: 10.1016/j.jacc.2013.08.1640.

21. Malik S, Budoff MJ, Katz R, Blumenthal RS, Bertoni AG, Nasir K, Szklo M, Barr G, Wong ND. Impact of subclinical atherosclerosis on cardiovascular disease events in persons with metabolic syndrome and diabetes: the multiethnic study of atherosclerosis. Diabetes Care 2011;34:2285-90.

22. Silverman MG, Blaha MJ, Budoff MJ, Rivera JJ, Raggi P, Shaw LJ, Berman D, Callister T, Rumberger JA, Rana JS, Blumenthal RS, Nasir K. Potential implications of coronary artery calcium testing for guiding aspirin use among asymptomatic individuals with diabetes. Diabetes Care 2012;35:624-6.

23. Blaha MJ, Blumenthal RS, Budoff MJ, Nasir K. Understanding the utility of zero coronary calcium as a prognostic test: a Bayesian approach. Circ Cardiovasc Qual Outcomes 2011;4:253-6.

24. Nasir K, Clouse M. Role of nonenhanced multidetector CT coronary artery calcium testing in asymptomatic and symptomatic individuals. Radiology 2012;264:637-49.

25. Nasir K, Shaw LJ, Budoff MJ, Ridker PM, Peña JM. Coronary artery calcium scanning should be used for primary prevention: pros and cons. JACC Cardiovasc Imaging 2012;5:111-8.

26. Nasir K, Martin SS, Virani S. Discordance: can we capitalize on it to better personalize atherosclerosis treatment? Atherosclerosis 2013;2013:504-6 